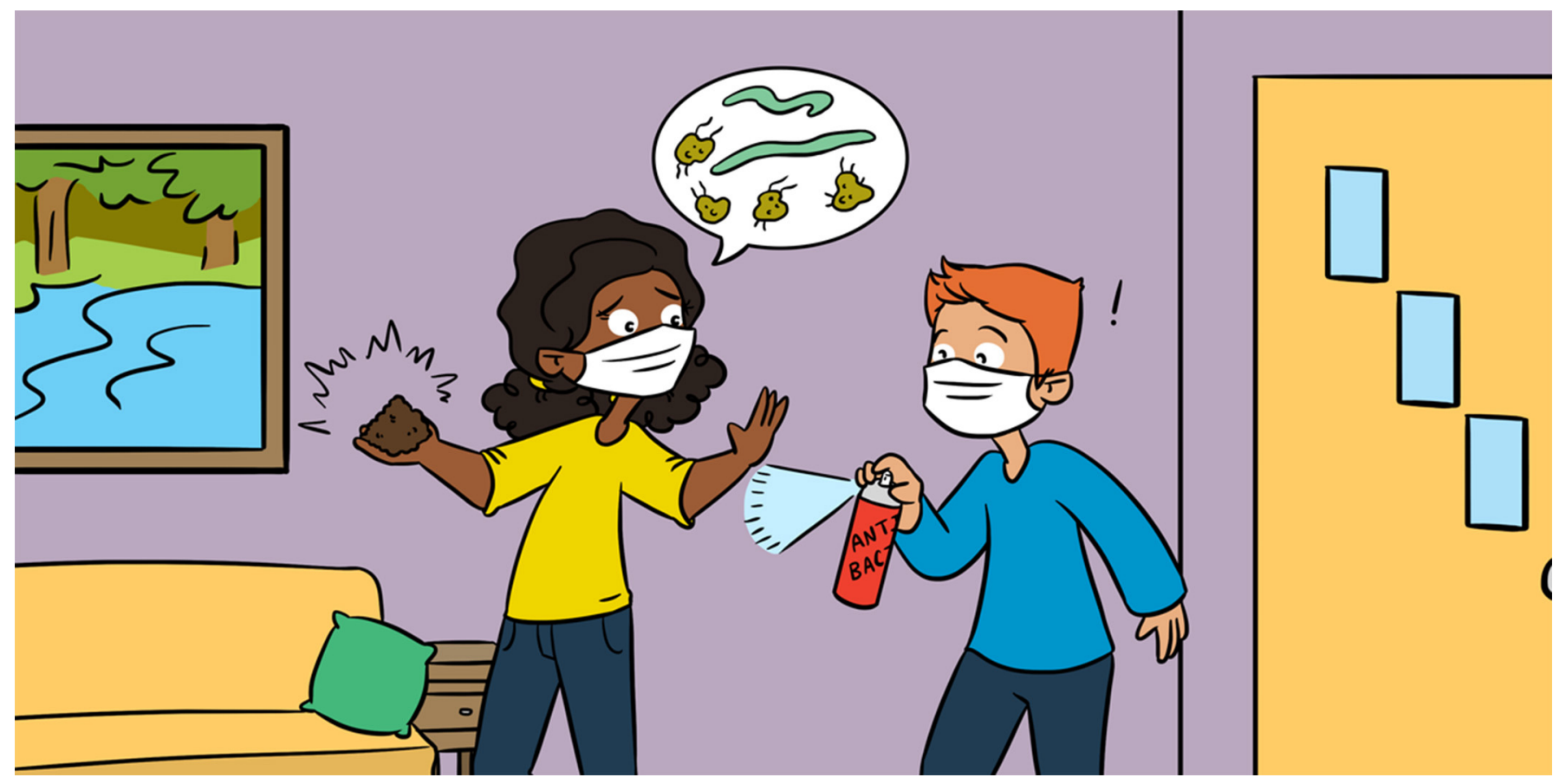

\title{
SUPER-SMALL PREDATORS IN SOILS: WHO ARE THEY AND WHAT DO THEY DO?
}

\section{Stefan Geisen ${ }^{1,2^{*}}$}

${ }^{1}$ Laboratory of Nematology, Wageningen University, Wageningen, Netherlands

${ }^{2}$ Department of Terrestrial Ecology, Netherlands Institute of Ecology NIOO-KNAW, Wageningen, Netherlands

YOUNG REVIEWER:

AYA

AGE: 10
There are millions of species living in soils. Most of this biodiversity is made up of bacteria and fungi, tiny organisms that make up what is called the soil microbiome. The size and composition of the soil microbiome is mainly controlled by two groups of predators: protists and nematodes. Protists are tiny single-celled organisms, while nematodes are tiny worms and the most numerous animals on Earth. Protists and nematodes together weight more than all the other animals on Earth! Protists and nematodes keep the soil microbiome in balance, which helps plants to grow and keeps soils functioning properly. Without protist and nematode soil predators, the functions and services provided by soils would change so much that it could even affect the Earth's climate. So, let us not forget the importance of these tiny soil organisms! 


\section{BIODIVERSITY}

The variety of species in an ecosystem.

\section{SOIL MICROBIOME}

All the microorganisms that live in the soil.

\section{MICROBIOME} PREDATORS

Organisms that feed on bacteria and fungi.

\section{MICROORGANISMS}

Tiny organisms, including bacteria, fungi, and protists.

\section{NEMATODES}

Tiny worms that live in all environments and inside hosts. Most abundant animals on Earth.

1 For an overview of nematode diversity, see https://www. wur.nl/en/ResearchResults/Chair-groups/ Plant-Sciences/ Laboratory-ofNematology/Nema tode-in-the-picture/ Nematode-Pictures. htm.

\section{PROTISTS}

All eukaryotes except for fungi, animals and plants, most of which are single celled.

\section{EUKARYOTES}

Organisms that have nuclei in their cells, in which DNA is located Eukaryotes include fungi, protists, plants, and animals.

\section{SOIL BIODIVERSITY}

Maybe you already know that soils are not just dark-colored dirt consisting of sand, clay, and loam; soils have high biodiversity, meaning that millions of organisms of all types and sizes live there. Not only do soils have more biodiversity than any other ecosystem on Earth, but the weight of all soil organisms (including plants whose roots make them about half soil organisms) is far greater than the weight of all other organisms combined [1]. Soil organisms range in size from microscopic viruses to huge fungi that can spread over hundreds of meters - and everything in between! The microscopic life in soils is called the soil microbiome, and it is mostly composed of bacteria and fungi. Without its biodiverse microbiome, soils would not be able to recycle nutrients and promote plant growth. This article focuses on two groups of soil organisms that few scientists study: protist and nematodes. By the time you are done reading, I hope you will understand why more research should focus on those tiny organisms!

\section{PROTISTS AND NEMATODES: TINY PREDATORS}

Microbiome predators are organisms that feed on microorganisms, such as bacteria and fungi [2]. Protists and nematodes are among the most important microbiome predators. Nematodes are super small-at least 100 times smaller than the width of a human hair-so they are not visible by the naked eye. The nematode most well-known to scientists is a roundworm that scientist call Caenorhabditis elegans, which is frequently used in research. Many scientists, doctors, farmers, and gardeners know nematodes as pests, because some species can infect humans, while others cause plant diseases. In soils, nematodes prey on bacteria, fungi, or other nematodes, and can be parasites of animals and plants. While most nematodes look basically the same, many hundreds of thousands of diverse species exist (Figure $1 \mathrm{~A})^{1}$. Eight of 10 animals on Earth are nematodes. In other words, 60 billion nematodes exist for every single human being [3]!

Now try to imagine that there are 1,000 times more protists than nematodes in soils! Protists are microorganisms that cannot be classified as animals or plants. Protists are eukaryotes, which means they contain a nucleus, just like the cells of animals, fungi, and plants. While the term "protist" might be new to you, you have probably heard of some well-known examples of protists: all eukaryotic algae that perform photosynthesis in lakes and oceans are protists. Some diseases are caused by protists, such as the malaria-causing Plasmodium falciparum. Amoebae and Paramecium are protists, and there are many more! It is likely that most of the eukaryotic diversity on Earth is composed of protists, with many millions of existing species. But we know fewer than 1 in 100 of the protist species that exist. In soils, protists perform a large range of functions. Most protists feed 
Figure 1

An impression of how nematodes (A) and protists (B) look like under the microscope. Similar to lions (C), which are well-known predators in savanna ecosystems,

microbiome predators

(D) have essential roles in underground ecosystems. These protists and nematodes feed on bacteria and fungi, changing the composition and activity these soil organisms, which helps to keep the soil healthy [image credits: $\mathbf{A}$ : nematodes (Anaplectus porosus and Aphelenchoides) in from Hanny van Megen]; (B) protists (Hyalosphenia papilio, Heliamoeba sp., and Mayorella viridis) from www.penard.de with permission from Eckhard Völcker and Steffen Clauß; (C) lion and zebra pictures from https://purepng.com/ (under CCO license).

(D) Bacterial cartoons under the CCO license from Wikipedia.

2 For an overview of protist shapes, see http://www.penard.de/.

3 Here is an online guide: https://www.ars. usda.gov/northeastarea/beltsville-mdbarc/beltsvilleagricultural-researchcenter/mycology-andnematology-geneticdiversity-and-biologylaboratory/people/zaf ar-handoo/extractingnematodes-from-soilsamples/!
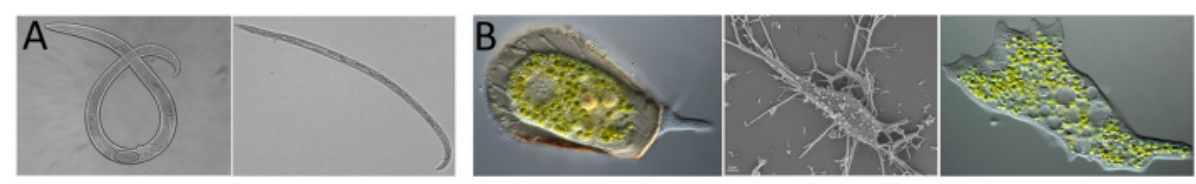

C
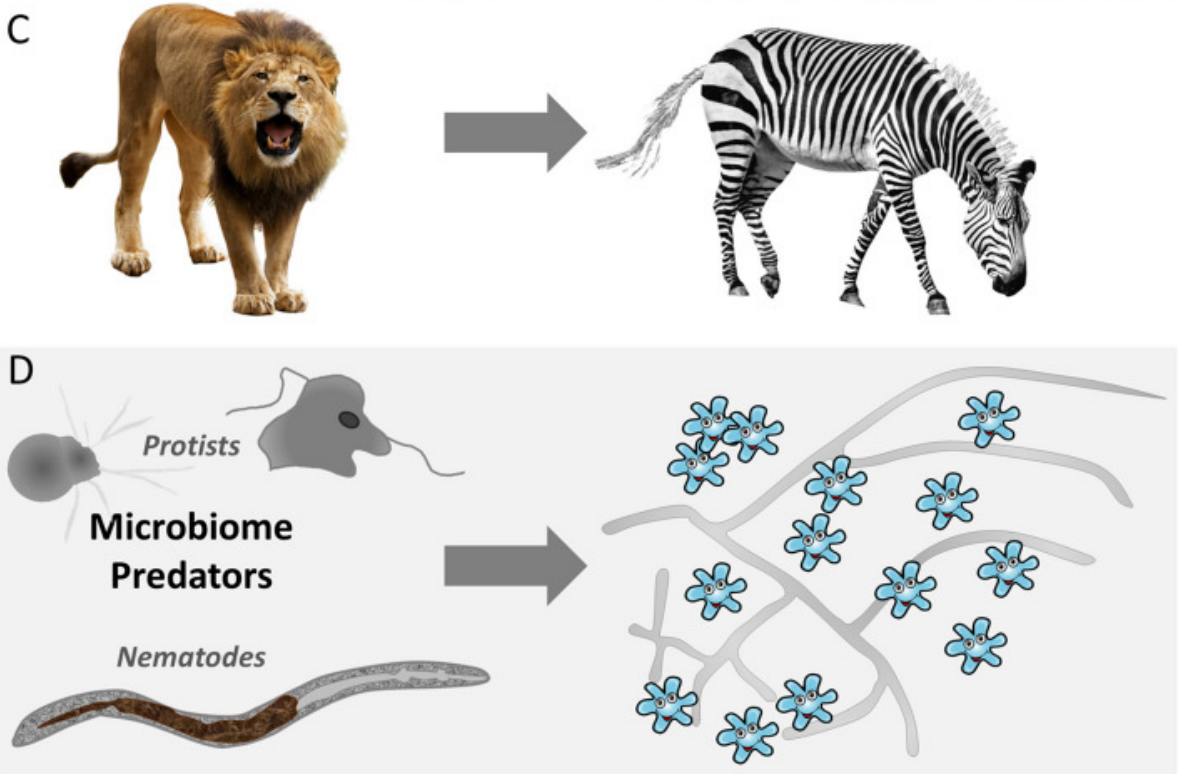

Figure 1

on bacteria, but many also feed on fungi or even on bigger animals. Some protists can be parasites of plants and animals, and some live in relationship with fungi, as lichens [4]. Protists have super diverse shapes and can be beautiful (Figure 1B) ${ }^{2}$.

Similar to lions or other large predators, microbiome predators prey on many things they can catch (Figures $1 C, D$ ). By doing so, these small predators control microbial growth, change the kinds of organisms present in the soil ecosystem, and help the soil to perform its important functions. Microbiome predators commonly feed on the less active microbes, thereby keeping the entire microbiome more active - a feeding strategy again similar to lions that induce prey fitness by feeding on older, slower, and weaker individuals. Microbiome predation also leads to a release of nutrients into soils, which can be taken up by other microbes and plants, helping these organisms to grow.

\section{HOW CAN WE STUDY MICROBIOME PREDATORS?}

Since nematodes and protists are tiny and not visible in soils, scientists face the big problem of not being able to directly study them in their natural habitat. One way to study these organisms is to isolate them from the soil. This is a bit easier for nematodes, and you can even try it yourself at home, using coffee filters or tissue paper, water, and a bowl (Figure 2$)^{3}$. 
Figure 2

Nematode extraction at home. Place a handful of soil in two coffee filters on top of each other, close them with clothespins as shown, and place the filters in a bowl filled with water (the water should cover the soil in the filter). The next day, remove the coffee filters, mix the solution and transfer it to a thin glass. Wait and hour, then carefully pour off most of the liquid, leaving only a little in the bottom of the glass. You can now observe nematodes in the remaining solution with a magnifying glass or microscope.

\section{DNA SEQUENCING}

A method to determine the DNA sequence of organisms. It can be used to identify organisms.

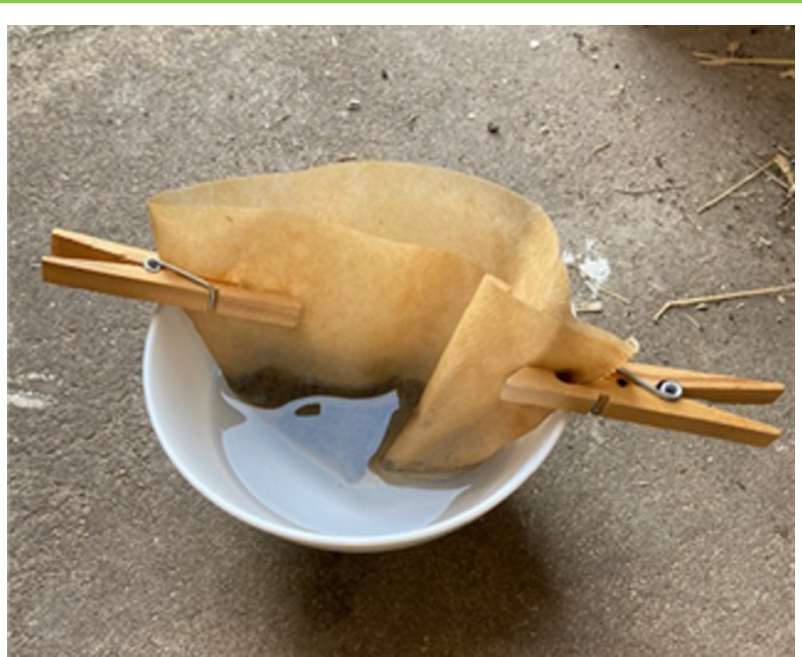

Figure 2

Studying protists is more complicated. Since most soil protists stick strongly to soil particles, the best way to study them in the past was to place tiny amounts of soil together with bacteria, to extract the bacteria-eating protists. However, only few types of protists can be grown this way, and therefore many protist species still are unknown. Today, most researchers use molecular tools to identify soil organisms. Like criminal investigators, we can use DNA extracted from soil to identify these small organisms. Since every organism has a unique DNA sequence, we can use a DNA sequencing technology to differentiate individual species based on their unique DNA. This can tell us which soil organisms are present, even though we cannot see them with our eyes or grow them in the lab (Figure 3).

These extraction, cultivation, and sequencing approaches show us which species are present in a soil sample, but not what these species do. There are ways to understand the functions of protists and nematodes in soils, including combining predators with various prey microorganisms to observe how they interact. Other scientific approaches can reveal what organisms feed on in soils, by tracing certain soil compounds using special methods as described in [5].

\section{WHY SHOULD WE CARE ABOUT MICROBIOME PREDATORS?}

Without microbiome predators, our soils would have a big problem... and a problem with the soil would cause problems for us! Almost all nutrients that enter soils are taken up by bacteria and fungi. If bacteria in soils were not controlled, the most numerous ones would take up all the nutrients and retain them for long periods. Microbes can remain alive in soils for months without predators, and can even enter a long-term survival stage, in which they can survive for decades. 
Figure 3

In addition to being well hidden in the soil, microbiome predators are too small to be seen by the naked eye. Scientists often study these organisms by extracting DNA from soils and sequencing that DNA to identify all the species of protists and/or nematodes that are present limage credit: https://www. bioanalysis-zone.com/ and copyright free(CCO)].

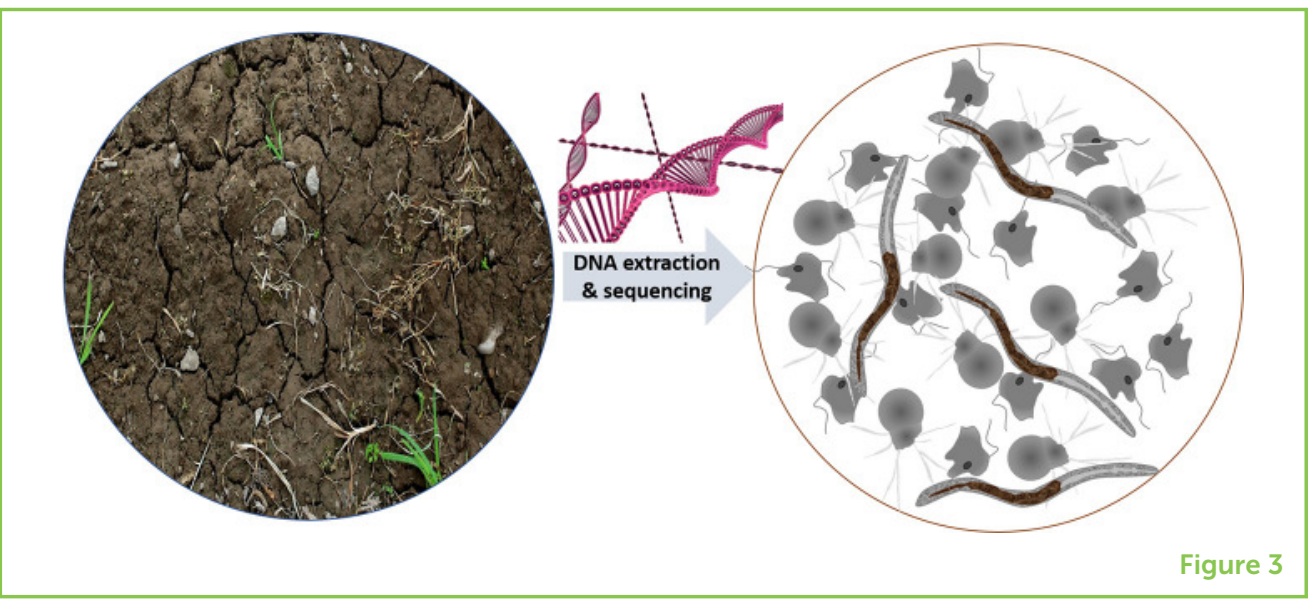

As a consequence, the food chain would stop and bigger organisms could not survive. Plants would also take up much less nutrients from soils and would grow slowly, if at all. Microbiome predators make sure that this situation does not happen. By preying on microbes and releasing some of the nutrients that those microbes take up, microbiome predators ensure that plants can access nutrients. The microbiome predators themselves can also serve as prey for larger organisms. So, microbiome predators ultimately save our food supply, by helping the soil to perform its critical functions.

\section{CONCLUSIONS}

Protists and nematodes are among the most biodiverse and numerous organisms on Earth. Both protists and nematodes are important microbiome predators and ensure that soils function the way they should. Simply said, without microbiome predators, life in and on soils would not be possible! Indeed, microbiome predators are of key importance for plant growth and they also play critical roles in other microbial processes that occur in healthy soils. By increasing our knowledge about microbiome protists and nematodes, we will also increase our understanding of how soils work. If we can learn how to adjust the types and numbers of microbiome predators in soils, we could help to keep the soil microbiome healthy and protect soil functions. The crucial role of microbiome predators in soils clearly shows that we should not forget any group of life on the planet, because even the smallest organisms can have a unique functional importance that helps to keep many other organisms, including humans, alive!

\section{REFERENCES}

1. Bar-On, Y. M., Phillips, R., and Milo, R. 2018. The biomass distribution on Earth. Proc. Natl. Acad. U.S.A. 115:6506-11. doi: 10.1073/pnas.1711842115 
2. Thakur, M. P., and Geisen, S. 2019. Trophic regulations of the soil microbiome. Trends Microbiol. 27:771-80. doi: 10.1016/j.tim.2019.04.008

3. van den Hoogen, J., Geisen, S., Routh, D., Ferris, H., Traunspurger, W., Wardle, D. A., et al. 2019. Soil nematode abundance and functional group composition at a global scale. Nature 572:194-98. doi: 10.1038/s41586-019-1418-6

4. Geisen, S., Mitchell, E. A. D., Adl, S., Bonkowski, M., Dunthorn, M., Ekelund, F., et al. 2018. Soil protists: a fertile frontier in soil biology research. FEMS Microbiol. Rev. 42:293-323. doi: 10.1093/femsre/fuy006

5. Erktan, A., Pollierer, M., and Scheu, S. 2020. Soil ecologists as detectives discovering who eats whom or what in the soil. Front. Young Minds 8:544803. doi: $10.3389 /$ frym.2020.544803

SUBMITTED: 21 August 2020; ACCEPTED: 07 October 2021; PUBLISHED ONLINE: 23 November 2021.

EDITED BY: Rémy Beugnon, German Centre for Integrative Biodiversity Research (iDiv), Germany

CITATION: Geisen S (2021) Super-Small Predators in Soils: Who Are They and What Do They Do? Front. Young Minds 9:597620. doi: 10.3389/frym.2021.597620

CONFLICT OF INTEREST: The author declares that the research was conducted in the absence of any commercial or financial relationships that could be construed as a potential conflict of interest.

COPYRIGHT @ 2021 Geisen. This is an open-access article distributed under the terms of the Creative Commons Attribution License (CC BY). The use, distribution or reproduction in other forums is permitted, provided the original author(s) and the copyright owner(s) are credited and that the original publication in this journal is cited, in accordance with accepted academic practice. No use, distribution or reproduction is permitted which does not comply with these terms.

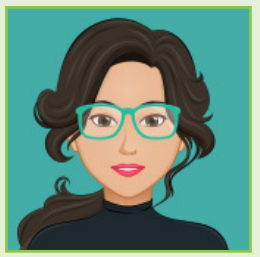

\section{YOUNG REVIEWER}

\section{AYA, AGE: 10}

Aya wants to study marine biology. She wants to specialize in sharks and rays. Her favorite subjects in school are reading, writing, math, and music. In her free time she likes to read books, try out challenging puzzles, train for track and cross country, and play the violin.

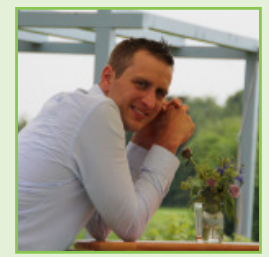

\section{AUTHOR}

\section{STEFAN GEISEN}

Stefan is an Assistant Professor at the Laboratory of Nematology at Wageningen University, the Netherlands. He tries to make sense of all the living organisms in soil. 
Meaning, he wants to explore what lives in soil and what these organisms do for the ecosystem and for us by steering plant growth. A major focus of his work is on protists and nematodes, small organisms that are the most important predators of microbes in soil. He is father of three boys and in the remaining time he likes to meet friends and do sports. *stefan.geisen awur.nl 